\title{
The Potential of a Water-in-Diesel Emulsion for Increased Engine Performance and as an Environmentally Friendly Fuel
}

\author{
N. H. Abdurahman ${ }^{1}$, Y. M. Rosli ${ }^{1}$, N. H. Azhari ${ }^{2}$ and A. Abdul Adam ${ }^{3}$ \\ ${ }^{1}$ Facuty of Chemical and Natural Resources Engineering, University of Malaysia Pahang-UMP, Malaysia \\ ${ }^{2}$ Faculty of Industrial Sciences and Technology, University of Malaysia Pahang-UMP, Malaysia \\ ${ }^{3}$ Faculty of Mechanical Engineering, University of Malaysia Pahang-UMP, Malaysia
}

\begin{abstract}
With increasing energy prices and the drive to reduce $\mathrm{CO}_{2}$ emissions, universities and industries face the challenge of finding new technologies to reduce energy consumption, to meet legal emission requirements and to reduce cost while increasing quality. In this study, an experiment was conducted to investigate the effect of water-indiesel (WiDE) emulsions on the combustion performance and emulsion characteristics of a direct injection diesel engine under 0 to $50 \%$ engine loads at 0 to $300 \mathrm{psi}$ with engine operating speeds of 1200 to $2500 \mathrm{rpm}$. The five types of emulsified diesel fuel used in this study consisted of WiDE- $5 \%$, WiDE- $10 \%$, WiDE- $20 \%$, WiDE- $30 \%$ and WiDE$40 \%$ with $3 \%$ of the surfactants tested. The results show that $15-85 \%$ emulsion diesel fuel is comparable and compatible with pure diesel. The power curve shows the emulsion diesel to be relatively similar to pure diesel, but with slightly higher results at $0 \%(0 \mathrm{psi})$. The torque curve at $0 \%$ also shows the emulsion diesel to be similar to pure diesel where the $15-85 \%$ torque is higher than that of pure diesel. The engine torque, power and brake efficiency increase as the water percentage in the emulsion increases. The $\mathrm{NO}$ and $\mathrm{CO}_{2}$ emission results of the $15-85 \%$ fuel were better than that of pure diesel; however, the $\mathrm{CO}$ emissions were higher, especially at higher engine speeds.
\end{abstract}

\section{Introduction}

Emulsions of water in diesel for use in internal combustion engines are easily applicable alternative fuels for existing vehicle fleets. Emulsion fuel is defined as an emulsion of water in standard diesel fuel with specific additives and surfactants to stabilize the system. There is growing interest in the use of diesel emulsions, and the environmental aspects are the main driving force behind the attention. The presence of water has a significant effect on several emission constituents, including exhaust gases, such as nitrogen oxides (both $\mathrm{NO}$ and $\mathrm{NO}_{2}$, which are collectively referred to as NOx) and carbon monoxide (CO), as well as black smoke and particulate matter. There may be a certain loss in engine performance due to the presence of water, but the diesel consumption is often reduced. The typical water content of the diesel emulsions is between 10 and $20 \%$. Both the global and local effects of environmental emissions are of concern when using alternative vehicle fuels. The global effect due to the gradual increase of atmospheric $\mathrm{CO}_{2}$ was the decisive factor behind the 1997 Kyoto Protocol. In the transport sector, the use of renewable fuels is the most effective way to limit the net increase of atmospheric $\mathrm{CO}_{2}$. In addition, the replacement of diesel and gasoline by natural gas will reduce $\mathrm{CO}_{2}$ emissions because of the lower carbon-to-hydrogen ratio in natural gas; however, the gain is much less than that of renewable fuels. The primary focus of the effect of local emissions is placed on the health hazardous $\mathrm{NO}_{\mathrm{x}}$ and the particulate matter emissions. For new engines, these emissions are strictly regulated by legislation. In Euro 4 (2005) and in Euro 5 (2008), the emissions of $\mathrm{NO}_{\mathrm{x}}$, particulate matter, hydrocarbons and carbon monoxide are clearly regulated; for existing vehicles, other rules apply.

There is growing interest in the use of diesel emulsions, and the environmental aspects are the main driving force behind the attention. The presence of water has a significant effect on several emission constituents, including exhaust gases, such as nitrogen oxides (both $\mathrm{NO}$ and $\mathrm{NO}_{2}$, which are collectively referred to as $\mathrm{NOx}$ ) and carbon monoxide (CO), as well as black smoke and particulate matter. There may be a certain loss in engine performance due to the presence of water, but the diesel consumption is often reduced. The typical water content of the diesel emulsions is between 10 and $20 \%$. Both the global and local effects of environmental emissions are of concern when using alternative vehicle fuels. The global effect due to the gradual increase of atmospheric $\mathrm{CO}_{2}$ was the decisive factor behind the 1997 Kyoto Protocol. In the transport sector, the use of renewable fuels is the most effective way to limit the net increase of atmospheric $\mathrm{CO}_{2}$. In addition, the replacement of diesel and gasoline by natural gas will reduce $\mathrm{CO}_{2}$ emissions because of the lower carbon-to-hydrogen ratio in natural gas; however, the gain is much less than that of renewable fuels. The primary focus of the effect of local emissions is placed on the health hazardous $\mathrm{NO}_{\mathrm{x}}$ and the particulate matter 
emissions. For new engines, these emissions are strictly regulated by legislation. In Euro 4 (2005) and in Euro 5 (2008), the emissions of $\mathrm{NO}_{\mathrm{x}}$, particulate matter, hydrocarbons and carbon monoxide are clearly regulated; for existing vehicles, other rules apply.

The interest in water-in-diesel emulsions derives from the fact that water in the form of micrometre-sized droplets exerts various positive effects on fuel combustion. Water-in-oil emulsions have been formulated and evaluated for most types of fuels, ranging from light hydrocarbons to triglycerides. However, the main interest lies particularly in water-in-diesel emulsions because the high combustion temperature and high pressure that exist in diesel engines are particularly suitable for the concept. This idea was experimentally discovered [1] and theoretically verified [2] nearly 30 years ago. The use of diesel emulsions provides several interesting effects, including reduced nitrogen oxide (NOx) emissions, lower soot and particulate contents in the exhaust, and improved combustion efficiency. The presence of water in diesel fuels brings about a considerable reduction in NOx and particulate matters (PM) emissions [3-8]. The effect on emissions is the main reason for the large interest in diesel emulsions today. It has been reported that $15 \%$ water in diesel fuel can reduce nitrogen oxide (NOx) emissions up to $35 \%$ under regular conditions [9]. Other authors have reported such reduced levels of NOx [5, 10-13]; however, these results relate to diesel and other lighter hydrocarbon fractions with very low nitrogen contents. For fuels with high nitrogen contents, such as some residual oils, the NOx in the exhaust mainly comes from the oxidation of the nitrogen-containing fuel components. In such cases, the emulsified water only has a small effect on the NOx level [14]. For diesel fuels, there may be a concomitant increase in the emission of carbon monoxide (CO) as well as in hydrocarbons [9]. The amount of PM in the exhaust from fuels with high nitrogen contents is normally significantly reduced [14]. Experimental studies have been performed on the effect of water in the form of a water-in-diesel emulsion on the formation of polycyclic aromatic hydrocarbons, some of which are known to be mutagenic [15]. Emulsion fuels produced lower amounts of polycyclic aromatic hydrocarbons in flames and reduced atmospheric emissions. A more specific analysis showed a decrease of two substances, pyrene and fluorene, when emulsion fuel was used. It is believed that micro-explosions promote the oxidation of hydrocarbons, possibly involving an attack by hydroxyl radicals. The reduced amount of the formed polycyclic aromatic hydrocarbons is likely to be one of the reasons for the lower amount of soot obtained with emulsion fuels because these hydrocarbons can be observed as precursors to soot particles.

\section{Materials and methods}

\subsection{Materials}

The oil samples used in this study were from commercial diesel. A detailed procedure for the preparation of water- in-diesel (W/D) emulsions and procedures, including the formation of the W/D emulsion, their characteristics and preparation methods, are thoroughly described in previous research by Abdurahman [16]. This paper merely describes the main experimental steps. The characteristics of the prepared emulsion are specified in Table 1. For preparation of water-in-diesel (W/D) emulsions, the agent-in-oil method was implemented. The emulsifying agent dissolved in the continuous phase (diesel) and water was gradually added to the mixture (diesel + emulsifying agent). The emulsions were vigorously agitated using a standard three-blade propeller at room temperature $(25-30)$. The prepared emulsions were used to check for w/o or o/w emulsions. All of the emulsions investigated were a type of water-in-oil emulsion (oil continuous phase). The properties of the water-in-diesel emulsions are listed in Table 2. The surfactant used in this study was Triton X-100 (polyethylene glycol octylphenyl ether), which has a chemical formula of $\mathrm{C}_{33} \mathrm{H}_{60} \mathrm{O}_{10}$. This surfactant is a nonionic hydrophilic surfactant that is suitable for use in the production of both $\mathrm{W} / \mathrm{O}$ and $\mathrm{O} / \mathrm{W}$ emulsions.

Table 1. Physical properties of the diesel fuel.

\begin{tabular}{|l|c|}
\hline Density at $20{ }^{\circ} \mathrm{C},\left(\mathrm{kg} / \mathrm{m}^{3}\right)$ & 840 \\
\hline Dynamic viscosity at $20{ }^{\circ} \mathrm{C}, \mathrm{mPas}$ & 6.5 \\
\hline Surface tension at $20{ }^{\circ} \mathrm{C}(\mathrm{mN} / \mathrm{m})$ & 29.4 \\
\hline Flash point, ${ }^{\circ} \mathrm{C}$ & 78 \\
\hline Initial boiling point, ${ }^{\circ} \mathrm{C}$ & 174.5 \\
\hline Final boiling point, ${ }^{\circ} \mathrm{C}$ & 380.3 \\
\hline
\end{tabular}

Table 2. Density of the diesel and WiDE emulsions ( $5 \%, 10 \%$, $20 \%, 30 \% \& 40 \%)$.

\begin{tabular}{|l|c|c|c|c|}
\hline Diesel & $\begin{array}{c}\mathbf{K g} / \mathbf{m}^{3} \text { at } \\
\mathbf{2 0} \\
\mathbf{8 4 0}\end{array}$ & $\begin{array}{c}\mathbf{K g} / \mathbf{m}^{\mathbf{3}} \text { at } \\
\mathbf{3 0}{ }^{\mathbf{0}} \mathbf{C} \\
\mathbf{8 3 5}\end{array}$ & $\begin{array}{c}\mathbf{K g} / \mathbf{m}^{\mathbf{3}} \text { at } \\
\mathbf{4 0}{ }^{\mathbf{0}} \mathbf{C} \\
\mathbf{8 2 8}\end{array}$ & $\begin{array}{c}\mathbf{K g} / \mathbf{m}^{\mathbf{3}} \text { at } \\
\mathbf{5 0}{ }^{\mathbf{0}} \mathbf{C} \\
\mathbf{8 2 0}\end{array}$ \\
\hline $\begin{array}{l}\text { WiDE- } \\
5 \%\end{array}$ & 848 & 842 & 835 & 828 \\
\hline $\begin{array}{l}\text { WiDE- } \\
10 \%\end{array}$ & 854 & 849 & 842 & 834 \\
\hline $\begin{array}{l}\text { WiDE- } \\
20 \%\end{array}$ & 870 & 865 & 858 & 850 \\
\hline $\begin{array}{l}\text { WiDE- } \\
30 \%\end{array}$ & 877 & 872 & 865 & 857 \\
\hline $\begin{array}{l}\text { WiDE- } \\
40 \%\end{array}$ & 930 & 925 & 918 & 910 \\
\hline
\end{tabular}

\subsection{Equipment and conditions}

In this study, the results of the formulation and evaluation of the $15-85 \%$ water-in-diesel emulsions with pure diesel were determined on a TF120M Yanmar engine. The engine sound was normal with no knocking. The experiments were conducted at $0 \%(0 \mathrm{psi})$ and $50 \%(300$ psi), while the engine speed ranged from 1200 to 2500 rpm. The power curve, torque curve, $\mathrm{NO}, \mathrm{CO} 2$, and $\mathrm{CO}$ results of WiDE were compared with traditional diesel fuel results. 


\section{Results and discussion}

\subsection{Emulsion diesel for fuel properties}

The stability of WiDE was investigated under the influence of the water concentration, surfactant concentration, mixing speed, viscosity, density and time. The most important factor of the emulsion preparation is the selection of a suitable surfactant or blend of surfactants that can satisfactorily emulsify the chosen ingredients at a specific temperature. Emulsification is greatly influenced by the hydrophilic-lipophilic balance (HLB) of any surfactant/emulsifier [16]. The percentage of water in the emulsion, stirring intensity, stirring duration, emulsifying temperature and operational pressure are other parameters that affect the stability of an emulsion. The WiDE prepared for the current study was observed for more than 65 days because it was emulsified and found to be stable for that period. It was noted that the larger the water content in the emulsion, the brighter and milkier the produced emulsion.

In this study, a wide range of water concentrations was investigated, from $0 \%$ to $40 \%$ by volume. Figure 1 shows the WiDE emulsion water content percentages versus the elapsed time for three samples with water concentrations of $5 \%, 20 \%$ and $40 \%$. These samples were prepared with no surfactant added at a mixing speed of $3000 \mathrm{rpm}$ for 20 minutes. Figure 1 shows that the percentage of water content within the three emulsions dropped very significantly over 15 minutes. The amount of separated water reached $27 \%, 50 \%$ and $80 \%$ for WiDE-5\%, WiDE-20\% and WiDE-40\%, respectively. Try to ensure that lines are no thinner than 0.25 point.

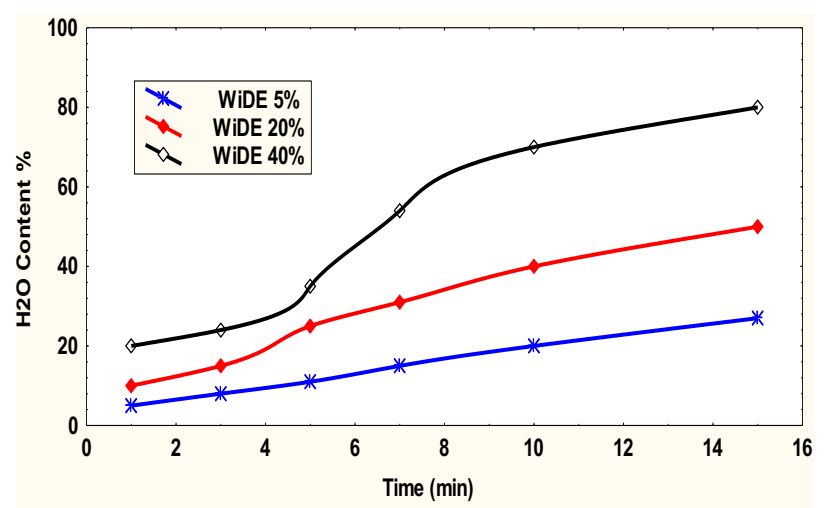

Figure 1. Emulsion behaviour without surfactant.

These samples show the strong unstable behaviour of water within WiDE emulsions, attributed to the absence of surfactants within the emulsion. Therefore, this preliminary study indicates that the presence of surfactant is crucial for WiDE emulsion stability. Figure 2 shows the effect of added water on the emulsion stability in the presence of a $3 \%$ Triton-X100 concentration.

The emulsion was prepared using a mixing speed of $3000 \mathrm{rpm}$ and was mixed for 20 minutes. Figure 2 shows that the WiDE-5\% and WiDE-20\% remained stable for 60 days before any water was separated. The WiDE-40 remained stable for 40 days before any water was separated.

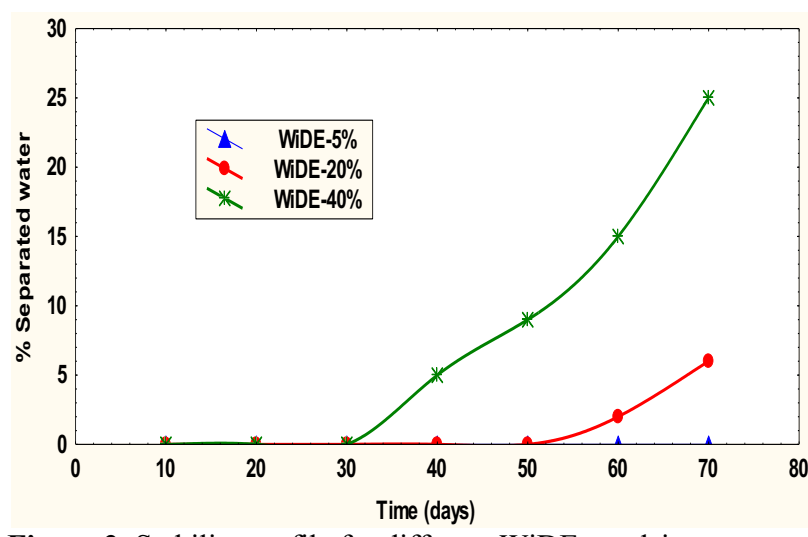

Figure 2. Stability profile for different WiDE emulsions.

\subsection{Diesel and engine performance}

The interest in water-in-diesel emulsions derives from the fact that water in the form of micrometre-sized droplets exerts some positive effects on fuel combustion. In this study, $15-85 \%$ water-in-diesel oil emulsions were formulated and evaluated using a TF120M Yanmar engine. The engine sound was normal with no knocking. The results show that the presence of water had a positive effect on the combustion efficiency of the engine. Figures 3 \& 4 show how $15-85 \%$ water in the form of an emulsion affects the engine torque output for various speeds (0 psi and $300 \mathrm{psi})$. A comparison was made between $15-85 \%$ WiDE and pure diesel performance on the TF120M Yanmar engine. Figure 3 illustrates the results with a $0 \%$ load $(0 \mathrm{psi})$; Figure 4 shows the performance of a $50 \%$ load (300 psi). In both figures, the torque increases as the engine speed increases. Interestingly, the engine with emulsion fuel is able to ingest a full charge of air compared to when traditional diesel fuel is used. This conclusion was supported by Abu-Zaid [17], who used the engine speed over a range from 1200 to $3300 \mathrm{rpm}$. However, Abu-Zaid found that at low speed, the torque increases as the engine speed increases. At approximately $1500 \mathrm{rpm}$, the torque begins to decrease because the engine is unable to ingest a full charge of air; these results are also in agreement with research by Harbach and Agosta [18].

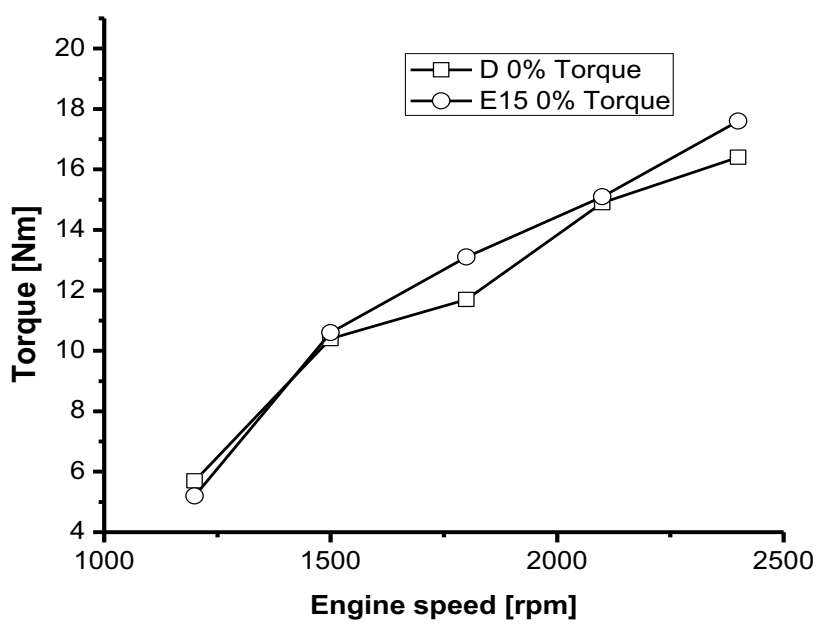

Figure 3. Engine torque output versus engine speed using water-in-diesel emulsions (0 psi). 


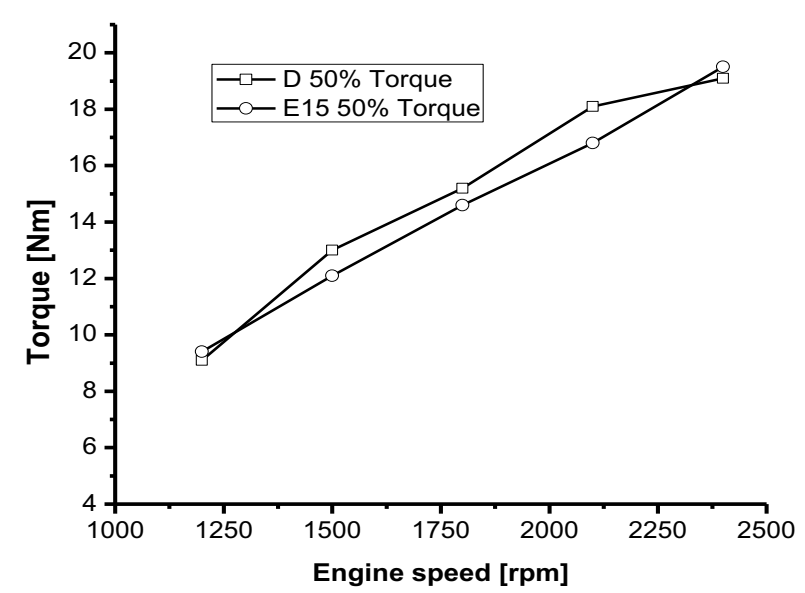

Figure 4. Engine torque output versus engine speed using water-in-diesel emulsions (300 psi).

It can be clearly observed from Figures $3 \& 4$ that the addition of water in the form of an emulsion has a positive effect on the combustion efficiency compared with the use of pure diesel, especially at 0 psi (Fig. 3).

The torque increases with the water content over the entire rpm range (1200 - $2500 \mathrm{rpm})$. When the charge is fired in the cylinder, the water turns into steam at high pressure. The combustion efficiency is also improved because of the presence of water and, in particular, the presence of the oil-water interface with a very low interfacial tension that leads to a finer atomization of the fuel during injection Walavalkar [19].

\subsection{Carbon dioxide emissions}

The formation of carbon dioxide $\left(\mathrm{CO}_{2}\right)$ reflects the complete combustion of the fuel; incomplete combustion typically reduces $\mathrm{CO}_{2}$ but increases the $\mathrm{CO}$ and hydrocarbon (HC) contents. The variation of $\mathrm{CO}_{2}$ emissions with the engine speed for the $15-85 \%$ emulsion fuel and pure diesel at ( 0 psi and 300 psi) is presented in Fig. 5. As shown in the figure, the $\mathrm{CO}_{2}$ content increases with engine speed and decreases with an increasing water content $(15 \%)$. The combustion of the emulsified fuels produces lower $\mathrm{CO}_{2}$ emissions compared to the combustion of pure diesel because the burning of the emulsified fuels generates a large number of microexplosions, leading to a greater mixing of the reactant mixture, Lin. et al [20].

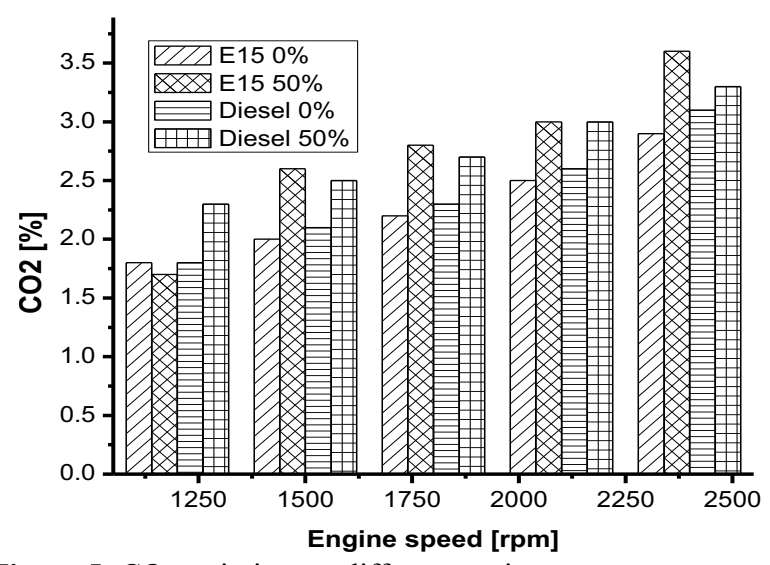

Figure 5. $\mathrm{CO}_{2}$ emissions at different engine.

\subsection{Nitrogen monoxide emission}

The variation of NO with engine speed for the addition of the $15 \%$ water emulsion and pure diesel is presented in Fig. 6. The engine speed has a minor effect on NO production compared with the water content in the fuel. The combustion of the emulsified fuel produced significantly less amounts of NO compared to pure diesel, possibly due to the finely dispersed water of the emulsion causing a phenomenon known as heat sink that reduces the local adiabatic flame temperature. These results also may due to the heat absorption by the water vaporization causing a reduction in the peak ignition temperature that further reduces NO formation, Kannan et al, [21].

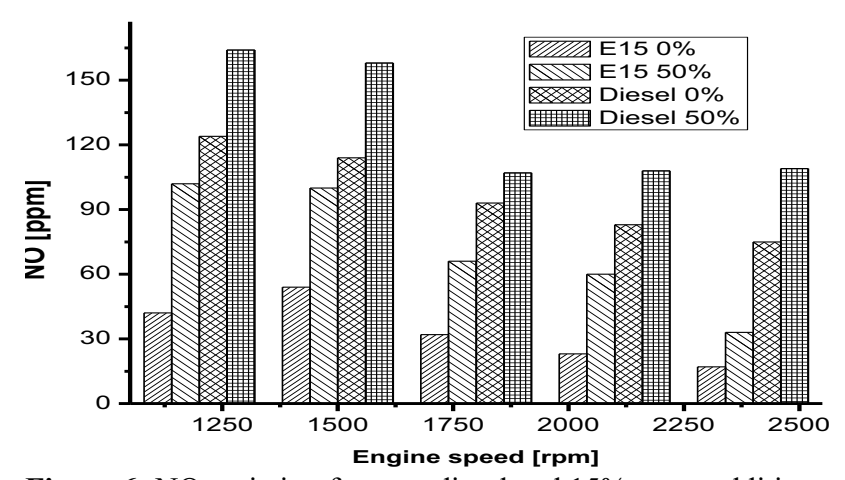

Figure 6. NO variation for pure diesel and $15 \%$ water addition.

\subsection{Engine power output}

The effect of the emulsions on the engine power is shown in Figures $7 \& 8$. The power increases as the engine speed increases, thus there is clearly no reduction of power within the experimental engine speeds (1200 $2500 \mathrm{rpm}$ ). These results may be attributed to the lack of friction losses with increased engine speed, which is not a dominant factor at high speeds. Observation has shown that the $15-85 \%$ emulsion fuel was very compatible with pure diesel, and in some cases, it is even better than pure diesel. The maximum power occurred at $2500 \mathrm{rpm}$, as illustrated in Figures $7 \& 8$, and the maximum torque $(20$ $\mathrm{Nm}$ ) occurred at a maximum engine speed of $2500 \mathrm{rpm}$, as presented Figs. $3 \& 4$. The power output increase for the emulsions resulted due to the influences of the water in the emulsion on fuel combustion. Harbach and Agosta [18] found that the introduction of water in diesel for a single cylinder engine prolongs the ignition delay.

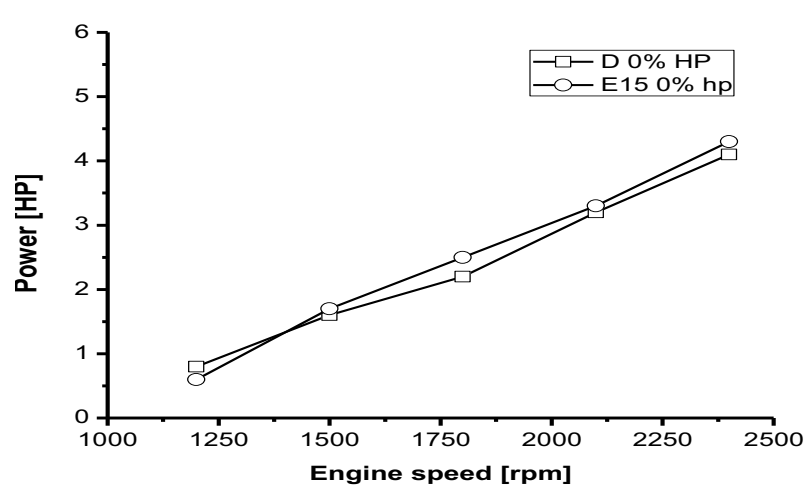

Figure 7. Engine power output versus engine speed using diesel-water emulsions ( $0 \%$ load). 


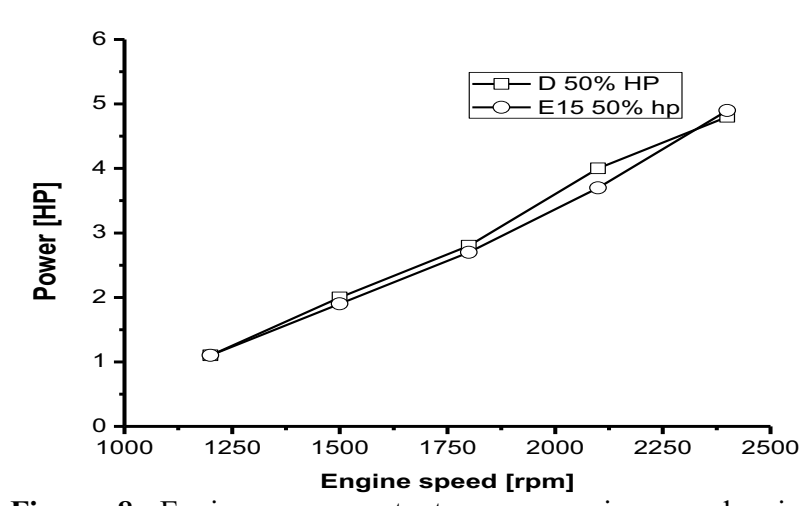

Figure 8. Engine power output versus engine speed using diesel-water emulsions (50\% loads).

\section{Conclusions}

In this study, an experimental investigation was conducted to examine the effect of water diesel emulsions on the performance of a TF120M Yanmar engine. The findings are summarized as follows:

- The addition of water in the form of an emulsion improves the combustion efficiency in the diesel engine, thus increasing the performance of the engine.

- Within a limited amount of running time during the engine tests ( $85 \mathrm{hrs}$.), no apparent wear, knocking or corrosion were observed.

- NO emissions were significantly reduced by using diesel water emulsions.

- CO emissions decreased with an increase in water percentage in the fuel.

- The water-in-diesel emulsion fuel is the best alternative fuel to substitute for diesel fuel in both transport and stationary CI engines because of the reduction in both $\mathrm{NO}_{\mathrm{x}}$ and $\mathrm{PM}$.

\section{References}

1. D. H. Cook, C. K Law, Combust Sci Technol 18, 217 (1978)

2. C. K. Law, Combust Sci Technol 17, 29 (1977)

3. J. M. Ballester, N. Fueyo, C. Dopazo, Fuel 75, 695 (1996)

4. R. W. Gunnerman, R. L. Russel, SAE Tech Pap (1997) 972099.
5. G. E. Andrews, S. W. Bartle, S. W. Pang, A. M Nurein, P. T. Williams, Proceedings of the International Centre for Heat and Mass Transfer, (Sept 1987). p. 613, (New York, NY, USA: Hemisphere Publ Corp; 1989)

6. W. Bernhardt, K. Weidmann, Erdol Kohle Erdgas Petrochem 40, 86 (1987)

7. D. Hall, C. Thorne, S. Goodier, SP-1802, 153 (SAE Spec Publ 2003)

8. M. Tsukahara, Y. Yoshimoto, International Congress and Exposition, Detroit 71, (Feb 24-28 1992)

9. A. Lawson, Vergeer EC, Mitchell EW, Dainty ED. Heavy-Duty Diesel Emission Control: A Review of Technology, vol. 36. Montreal, Quebec, Canada: CIM; 1986. p. 238.

10. J. W. Park, K. Y. Huh, J. H Lee, Proc Inst Mech Eng Part D J Automob Eng 215, 83 (2001)

11. E. M. Afify, Report ARO194353EG (DTIC No ADA-161-652). Raleigh, NC, USA: 106 (North Carolina State Univ., 1985)

12. F. Barnaud, P. Schmelzle, P. Schulz, SP-1551:95 (SAE Spec Publ 2000)

13. M. Fromager, P. Schmelzle, P. Schulz, 2nd International Symposium on Fuels and Lubricants, Symposium Papers, New Delhi, 2, 435 (Mar 10-12, 2000)

14. R. E. Hall, Trans ASME J Eng Power 98, 6425 (1976)

15. J. A. Kozinski, Combust Flame 96, 249 (1994)

16. H. N. Abdurahman, M. Y. Rosli, H. N. Azhari, Stabilization of crude oil Emulsions, Journal of Applied Sciences, 350-357 (2006).

17. Abu Zaid, M. Energy Convers Manag, 45, 697 (2004).

18. J. Harbach, V. Agosta, Effects of emulsified fuel on combustion in a four-stroke Diesel engines. J Ship Res, 35 (4), 356-63 (1991)

19. A. Y. Walavalkar, $\mathrm{PhD}$ Thesis, Pennsylvania State University (2001)

20. C. Y. Lin, K. H. Wang. The fuel properties of threephase emulsions as an alternative fuel for diesel engines. Fuel, 82, 1367-75 (2003)

21. T. K. Kannan, Thevetia, Peruviana. Biodiesel emulsion used as a fuel in a single cylinder diesel engine reduces NO and smoke, Thermal science. 15, 1185-1191 (2011) 